\title{
Remarks on Ambient Air Pollution and Health Outcomes
}

\author{
Mieczysław Szyszkowicz \\ Population Studies Division, Health Canada, Ottawa, ON, Canada K1A 0K9 \\ Correspondence should be addressed to Mieczysław Szyszkowicz; mietek.szyszkowicz@hc-sc.gc.ca
}

Received 29 April 2013; Accepted 26 June 2013

Academic Editors: R. S. Carel, T. Nawrot, and A. Rosano

Copyright (C) 2013 Mieczysław Szyszkowicz. This is an open access article distributed under the Creative Commons Attribution License, which permits unrestricted use, distribution, and reproduction in any medium, provided the original work is properly cited.

\begin{abstract}
Background. Ambient air pollution is a recognized risk factor for multiple health conditions. For some health problems, the impact of air pollution is particularly evident to the patients in a specific age range. Nonsimultaneous exposures to two or more air pollutants may have different relationships with health outcomes than do simultaneous exposures. Methods. Case-crossover technique was used to analyze data on emergency department (ED) visits for ischemic heart disease (IHD), epistaxis, and upper respiratory infection (URI). Conditional logistic regression models were used to estimate odds ratios and their $95 \%$ confidence intervals corresponding to an increase in an interquartile range of air pollutant concentrations. Results. The results for IHD show that for older patients (age 60+ years), the association between sulphur dioxide $\left(\mathrm{SO}_{2}\right)$ exposure and IHD is weak. For ED visits for epistaxis $\left(\mathrm{O}_{3}\right.$ and $\mathrm{SO}_{2}$ in one model $)$ and $\mathrm{URI}\left(\mathrm{O}_{3}\right.$ and $\mathrm{NO}_{2}$ in one model), air pollutants lagged differently in the common model indicated significant statistical associations but not for common lags. Conclusion. The study findings, based on analyzed examples, suggest that (i) IHD cases in older age are less related to air pollution and (ii) air pollutants may affect some health conditions by a specific sequence of exposure occurrences.
\end{abstract}

\section{Introduction}

Air pollution is a recognized risk factor for multiple health conditions, exacerbates disease states, and increases premature mortality [1-5]. In many epidemiological studies, age groups are defined a priori and, usually, persons of age greater than, say, 65 years of age (i.e., 65+) are considered and included in one group. It is an implicit assumption that air health effects are the same for all persons of this age and older. For some diseases, it may happen that in such a group the older persons are more affected by a preexisting disease itself rather than by an impact from environmental conditions. In this work, emergency department (ED) visits for ischemic heart disease (IHD) were considered in this context. The cases were identified using the ICD-9 codes 410-414 (the International Classification of Diseases, 9th Revision).

The second example is related to the situation when two air pollutants considered in the same model show different associations with health outcomes. Thus, for two air pollutants, say $\mathrm{X}$ and $\mathrm{Y}$, the configuration $\mathrm{X}$ (lag 0 ), $\mathrm{Y}$ (lag 0) may have a different association with the considered health endpoint than does the configuration X (lag 0), Y (lag 1). The air pollutants in the statistical model usually are included with the same or different lags. Exposure may be interpreted as simultaneous ( $\mathrm{X}$ and $\mathrm{Y}$ with the same lags) or nonsimultaneous (X and $\mathrm{Y}$ with different lags). In this case, two different health conditions are analyzed: (i) epistaxis (ICD-9: 784.7) for patients 18 years old and younger and (ii) upper respiratory infection (URI) identified with ICD-9 codes 460-465 and 472-474. Some combinations of lags may better represent the real situation, even in relations among two or more air pollutants, for example, high nitrogen dioxide concentration is usually followed by a high ozone concentration. Thus we expect that ozone (lag 0 ) and nitrogen dioxide (lag 1) are better representation than lag 1 for ozone and lag 0 for nitrogen dioxide.

\section{Materials and Method}

The health data for IHD were obtained from one of the hospitals in Toronto for the period April 1999-March 2002. Epistaxis and URI data were retrieved from ED database provided by a group of five hospitals in Edmonton for a 10-year 

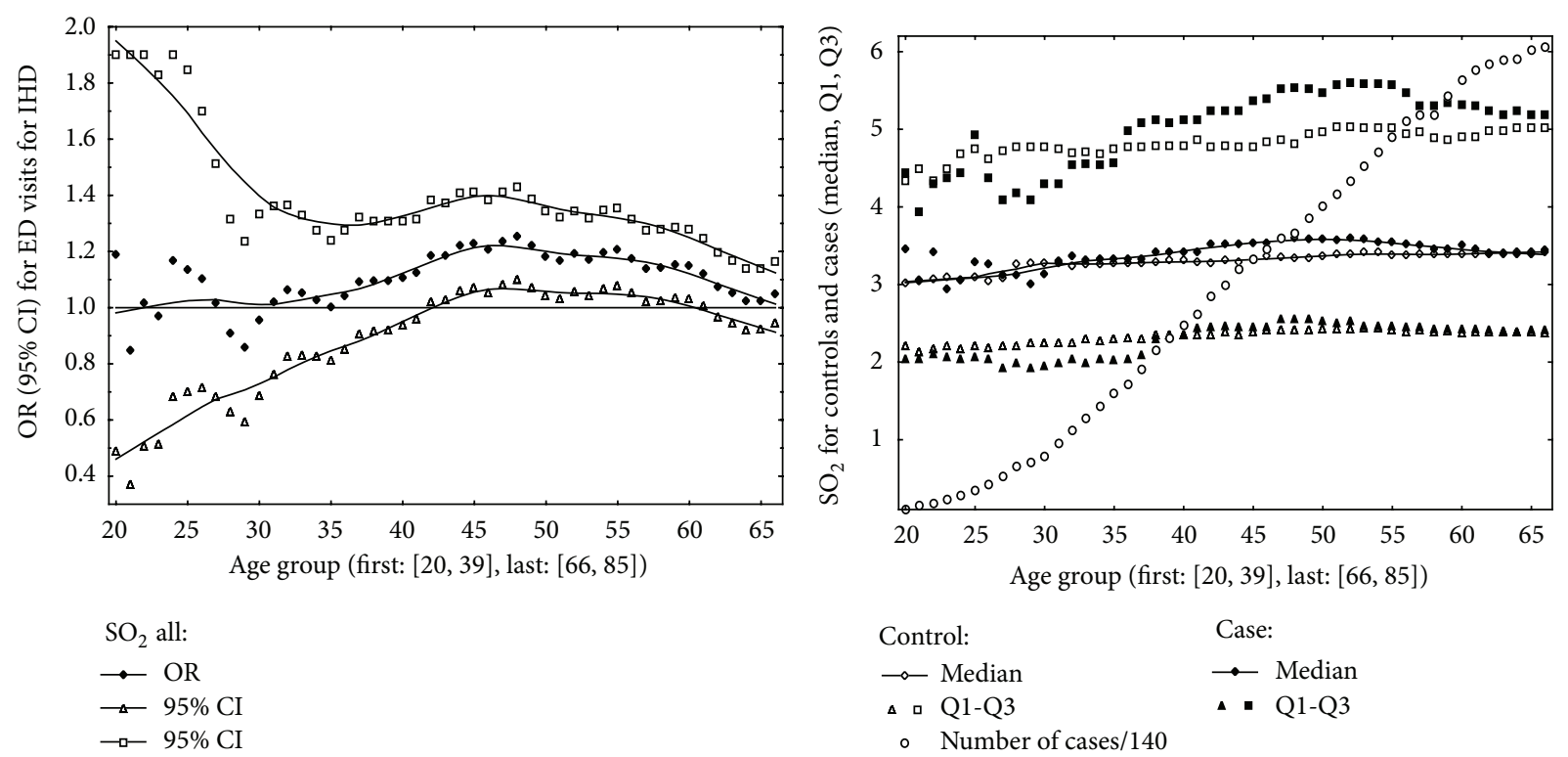

(a)

(b)

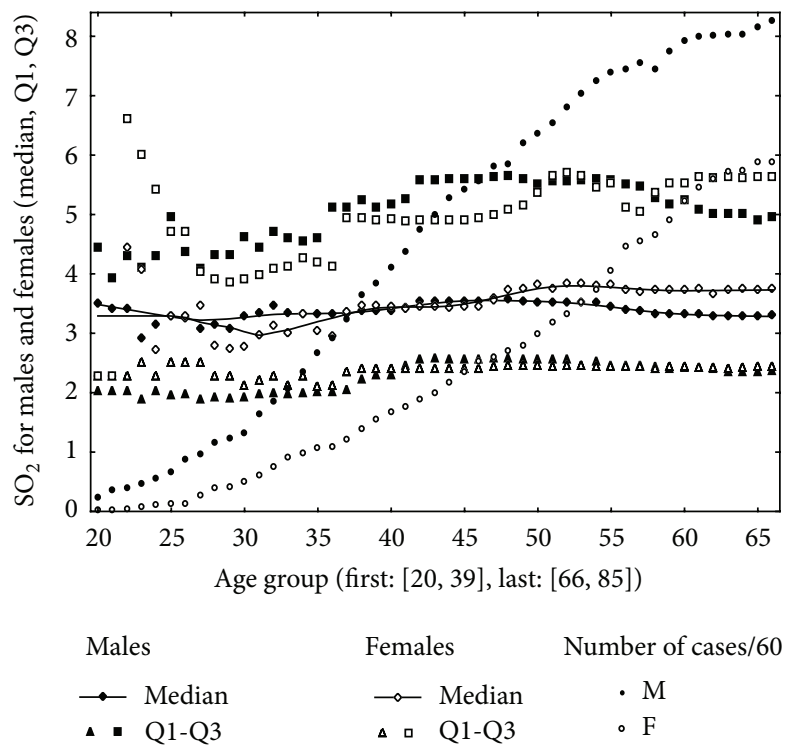

(c)

FIGURE 1: ED visits for ischemic heart disease (IHD). (a) Odds ratios (OR, 95\% CI) by age groups and (b) levels of $\mathrm{SO}_{2}$ by age group for cases and controls. (c) Levels of $\mathrm{SO}_{2}$ by age group for cases-shown by sex. The results are shown for the sequence of age groups: $[20,39],[21,40], \ldots,[66,85]$.

period (April 1992-March 2002). Associations between ambient air pollutants and the considered health outcomes were investigated using a case-crossover design ( $\mathrm{SO}_{2}$ with $\mathrm{IHD}$, $\mathrm{SO}_{2}$ and $\mathrm{O}_{3}$ with epistaxis, and $\mathrm{NO}_{2}$ and $\mathrm{O}_{3}$ with URI). This design is an adaptation of the case-control method, whereby cases serve as their own controls [6]. A subject's exposure to external factors at the time of a health event (case period) is compared with another period when the subject was a noncase (control period). Most time-invariant confounders are controlled by making within-subject comparisons. We used time-stratified approach to identify control periods. Similarly, the matching of control to case periods by day of week ostensibly controlled for the influence of day-of-week effects [7]. In our study, in the constructed models we adjusted for temperature and relative humidity in a nonlinear form. Both meteorological factors were included in the form of natural splines with 3 degrees of freedom.

The calculated OR for in emergency visits were estimated for an interquartile range $(\mathrm{IQR}, \mathrm{IQR}=\mathrm{Q} 3-\mathrm{Q} 1=75$ th-25th percentile) increase in air pollutant concentrations.

In the case of IHD, a sequence of overlapping age intervals was created to be able to investigate the relationship between ED visits and the age of patients. The sequence was defined as follows: $[20,39],[21,40], \ldots,[66,85]$ years. The analysis 


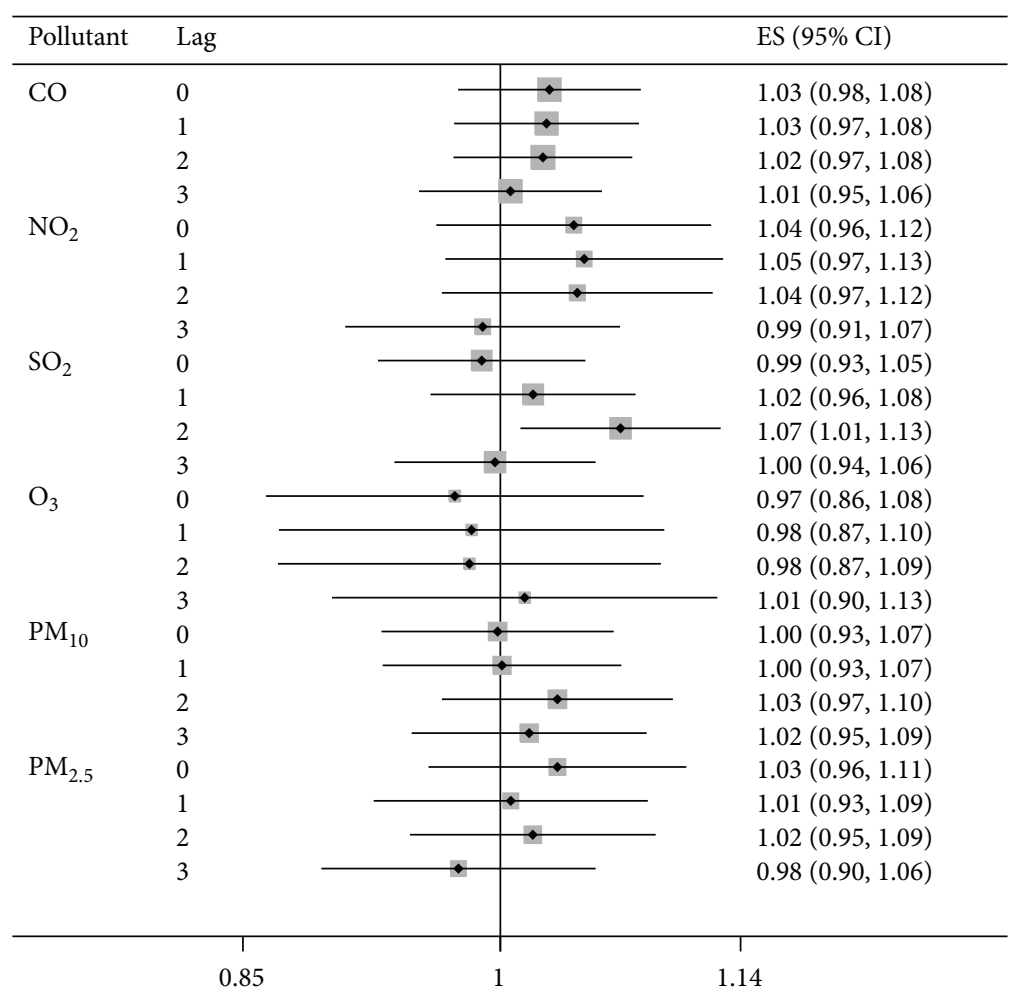

FIgURE 2: ED visits for epistaxis (age < 19 years). Odds ratios (OR, 95\% CI) estimated by single-pollutant models.

was performed separately for each age interval. In addition, the calculation was performed for patients in the age interval of $[20,85]$ years. For each age interval, the corresponding values of sulphur dioxide concentrations for both the case and matched-control periods were estimated and represented as Q1, median, and Q3. The daily mean value (24-hour average) was used to represent the $\mathrm{SO}_{2}$ level on a specific day. The same representation was used for other ambient air pollutants considered here.

\section{Results and Discussion}

3.1. Results for Ischemic Heart Disease (IHD). The results for IHD are reported in the form of one figure (Figure 1) with three panels $(\mathrm{a}-\mathrm{c})$. Figure $1(\mathrm{a})$ shows $\mathrm{OR}$ and their corresponding 95\% CI intervals for the sequence of overlapping age groups. These values are shown for $\mathrm{SO}_{2}$ for its IQR of $2.9 \mathrm{ppb}$. For all patients, that is, those in the age interval of $[20,85]$ years, the estimated OR $=1.12(95 \%$ CI: 1.02-1.23). Figure 1(b) illustrates the quartiles (Q1, Q3) and median for the pollutant levels by case/control period. Also, it illustrates the number of ED visits for IHD (scaled by 140 to fit into the figure). The number of ED visits for IHD increases with age. The estimated OR are large, and the $95 \%$ CIs are narrower with a growing number of cases. For older patients, we observe that OR are positive but not statistically significant. Figure 1(c) shows the values of sulphur dioxide concentrations by case period for males and females, respectively. The frequency of ED visits also is shown by sex and age group and is scaled by 60 to fit into the figure.
The illustration indicates that males of increasing age are less exposed than that females even the number of IHD cases is larger for males than that for females, and increases with age. In total there were 2,348 cases in the study. Daily mean value for $\mathrm{SO}_{2}$ was $4.2 \mathrm{ppb}$ with standard deviation $=2.6 \mathrm{ppb}$.

3.2. Results for Epistaxis. We considered ED visits for epistaxis for patients younger than 19 years of age. We identified 15,038 cases (males $=8,587$, females $=6,451$ ). As nose bleeding falls under two main categories in relation to age-anterior bleeds and posterior bleeds-we may observe different relationships with air pollutant concentrations by age. In this study our intention was to address only the methodological issue; thus, we do not go into much detail here. We focus our attention for ED visits for epistaxis among young persons. We studied primarily the relationship between two pollutants $\left(\mathrm{SO}_{2}\right.$ and $\left.\mathrm{O}_{3}\right)$ and epistaxis. We also considered other air pollutants to obtain more information on the associations with ozone.

For single-pollutant models-that is, each air pollutant was considered separately-we obtained the following results: for $\operatorname{lag} 0, \mathrm{OR}=0.982(95 \% \mathrm{CI}$ : $0.920-1.048$, for $\left.\mathrm{SO}_{2}\right), \mathrm{OR}=0.964\left(0.856-1.085\right.$, for $\left.\mathrm{O}_{3}\right)$; for lag $1, \mathrm{OR}=$ $1.018\left(0.954-1.085\right.$, for $\left.\mathrm{SO}_{2}\right), \mathrm{OR}=0.993(0.879-1.120$, for $\left.\mathrm{O}_{3}\right)$; and for lag $2, \mathrm{OR}=1.077\left(1.012-1.147\right.$, for $\left.\mathrm{SO}_{2}\right), \mathrm{OR}=$ 1.037 (0.919-1.170, for $\left.\mathrm{O}_{3}\right)$. The results for single-pollutant models are shown in Figure 2 for lags from 0 to 3 days. The figure also illustrates the results for four other air pollutants: carbon monoxide (CO), $\mathrm{NO}_{2}$, and particulate matter (PM) of different aerometric diameters (2.5 and 10 microns, resp.). We 


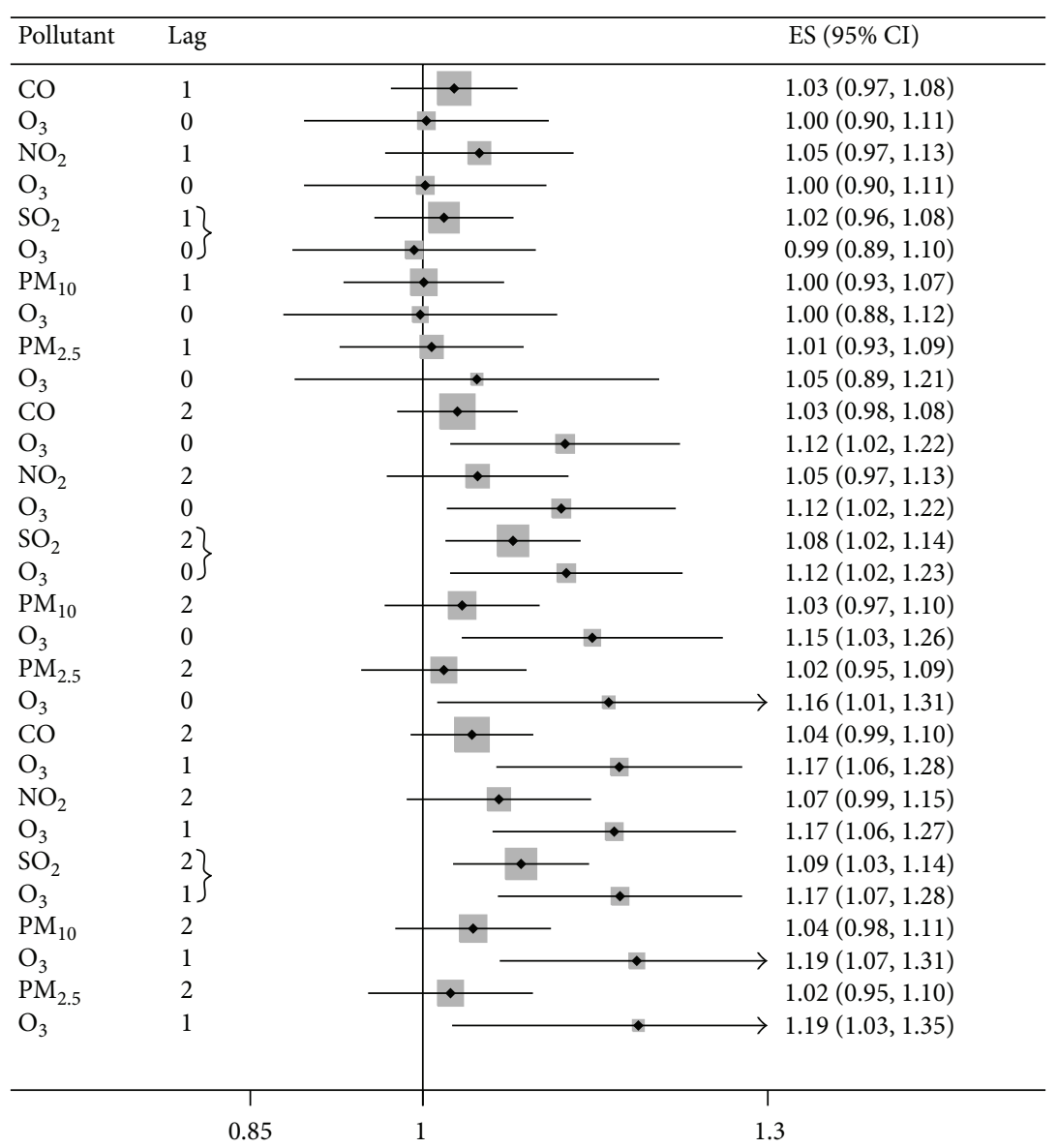

FIGURE 3: ED visits for epistaxis (age < 19 years). Odds ratios (OR, 95\% CI) estimated by two-pollutant models with different lags.

focused on $\mathrm{SO}_{2}$ and $\mathrm{O}_{3}$. Figure 3 shows the results for twopollutant models for different combinations of air pollutants and lags used in the common models. All the considered models were two-pollutant models with ambient ozone as the second pollutant. The strongest association was obtained for the two-pollutant model with $\mathrm{SO}_{2}$ and $\mathrm{O}_{3}$ lagged by 2 days and 1 day, respectively. This result is in contrast to that using single-pollutant models, where only one positive and statistically significant result was observed, that is, for sulphur dioxide with lag 2 but not for $\mathrm{O}_{3}$. The association for ozone was observed for older patients (age $>18$ years) and is thus probably an indication of a different type of epistaxis. The data are not shown here.

3.3. Results for Upper Respiratory Infection (URI). In case of ED visits for URI, we considered $\mathrm{NO}_{2}$ and $\mathrm{O}_{3}$, as both air pollutants usually are strongly correlated. Figure 4 shows the results for both pollutants considered in single-pollutant models (both lagged by the same number of days: 0 or 1 ) and in two-pollutant models. The two-pollutant models are indicated by rectangles. The brackets $[*]$ are used to indicate the specific pollutant for which the results are reported. We observed that in the case of two-pollutant models, when we used $\mathrm{O}_{3}$ exposure (lag 1) before $\mathrm{NO}_{2}$ exposure (lag 0 ), the result is weak. Such a configuration is less probable in nature, as nitrogen dioxide usually precedes ozone. It is opposite to the properly modelled situation: $\mathrm{NO}_{2}$ lagged by 1 day and $\mathrm{O}_{3}$ lagged by 0 day (same-day exposure).

The results for epistaxis and URI are reported for the following values of IQRs for the considered 6 air pollutants: $\left(\mathrm{CO}, \mathrm{NO}_{2}, \mathrm{SO}_{2}, \mathrm{O}_{3}, \mathrm{PM}_{10}, \mathrm{PM}_{2.5}\right)=(\mathrm{IQR}: 0.4 \mathrm{ppm}, 12.8 \mathrm{ppb}$, $\left.2.3 \mathrm{ppb}, 14.0 \mathrm{ppb}, 15.0 \mu \mathrm{g} / \mathrm{m}^{3}, 6.2 \mu \mathrm{g} / \mathrm{m}^{3}\right)$, respectively. The corresponding daily mean values were $0.7,21.9,2.6,18.6$, 22.6 , and 8.5, respectively. The correlation coefficients for the daily average values of air pollutant concentrations were as follows: $\mathrm{O}_{3}$-CO: $-0.55, \mathrm{O}_{3}-\mathrm{NO}_{2}:-0.53, \mathrm{O}_{3}-\mathrm{SO}_{2}:-0.27, \mathrm{O}_{3}$ $\mathrm{PM}_{10}:-0.07, \mathrm{O}_{3}-\mathrm{PM}_{2.5}: 0.05, \mathrm{CO}-\mathrm{NO}_{2}: 0.78, \mathrm{CO}-\mathrm{SO}_{2}: 0.43$, $\mathrm{CO}-\mathrm{PM}_{10}: 0.43, \mathrm{CO}-\mathrm{PM}_{2.5}: 0.32, \mathrm{NO}_{2}-\mathrm{SO}_{2}: 0.47, \mathrm{NO}_{2}-\mathrm{PM}_{2.5}$ : $0.39, \mathrm{NO}_{2}-\mathrm{PM}_{10}: 0.33, \mathrm{SO}_{2}-\mathrm{PM}_{2.5}: 0.21, \mathrm{SO}_{2}-\mathrm{PM}_{10}: 0.22$, and $\mathrm{PM}_{2.5}-\mathrm{PM}_{10}: 0.76$.

3.4. Discussion. We applied a widely accepted and often used statistical method, the case-crossover technique realized by using conditional logistic regression, to estimate odds ratios in relation to short-term exposure to air pollutants and associated health outcomes. We observed that for some health outcomes, in our case ED visits for IHD, the association with air pollution (here, $\mathrm{SO}_{2}$ ) decreases with age. It may be an effect that older persons are more protected from the effects of exposure to ambient air pollution by virtue of their lifestyle. They often spend more time at home, do not commute to work, and possibly stay away from more polluted areas. It also 


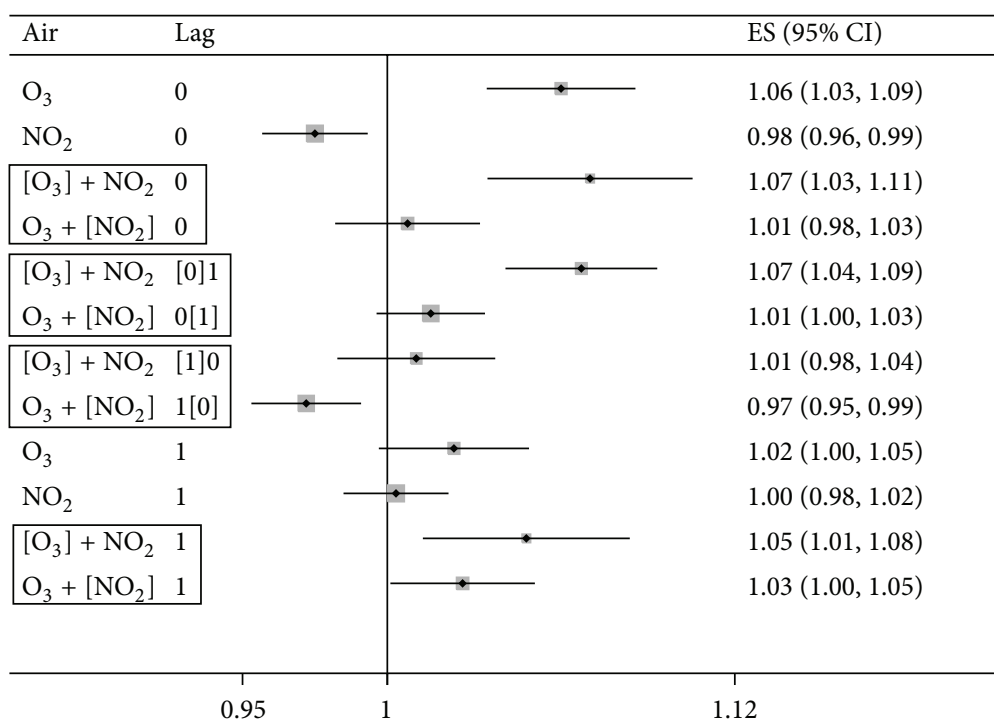

FIGURE 4: ED visits for upper respiratory infection (URI). Odds ratios (OR, 95\% CI) for different configurations (lags) of $\mathrm{O}_{3}$ and $\mathrm{NO}_{2}$ in the models.

may be a biological effect; that is, for older persons the disease itself affects their health without any environmental triggers, or possibly another trigger is stronger than exposure to air pollutants. In addition, the impact of lagged exposure (say, lag of 1 day) may be stronger than same-day exposure for older persons.

The second problem considered here is related to twopollutant models, where the applicable air pollutants were lagged by a different number of days. It may be viewed as modelling exposure to two pollutants in a time sequence. In the case of epistaxis, we observed associations for ozone and sulphur dioxide, lagged differently (ozone: 1 day; sulphur dioxide: 2 day). The association of ozone exposure and hospital epistaxis presentation was already observed and published [8].

The presented phenomenon (different lags in one model) is implicitly known and very often applied. It is in case of weather variables, for example, temperature. Even in one-pollutant models incorporating temperature, different approaches are usually used; temperature is considered on the day of the event or is lagged by the same number of days as the applicable air pollutant. Since temperature and air pollution are often correlated, the obtained results may differ from these two options [9].

The presented results may also be just an effect of the pure numerical properties of regression models where two pollutants are correlated or, as in case of single-pollutant models, where temperature and air pollutant are considered. Thus, two variables used in a common model and differently shifted by a few days by using lags may show a stronger association than those considered with the same lag.

\section{References}

[1] M. L. Bell, K. Ebisu, R. D. Peng et al., "Seasonal and regional short-term effects of fine particles on hospital admissions in
202 US counties, 1999-2005," American Journal of Epidemiology, vol. 168, no. 11, pp. 1301-1310, 2008.

[2] F. W. S. Ko, W. Tam, W. W. Tze et al., “Temporal relationship between air pollutants and hospital admissions for chronic obstructive pulmonary disease in Hong Kong," Thorax, vol. 62, no. 9, pp. 779-784, 2007.

[3] F. Dominici, R. D. Peng, M. L. Bell et al., "Fine particulate air pollution and hospital admission for cardiovascular and respiratory diseases," Journal of the American Medical Association, vol. 295, no. 10, pp. 1127-1134, 2006.

[4] J. M. Samet, F. Dominici, F. C. Curriero, I. Coursac, and S. L. Zeger, "Fine particulate air pollution and mortality in 20 U.S. cities, 1987-1994," The New England Journal of Medicine, vol. 343, no. 24, pp. 1742-1749, 2000.

[5] C. A. Pope III, R. T. Burnett, G. D. Thurston et al., "Cardiovascular mortality and long-term exposure to particulate air pollution: epidemiological evidence of general pathophysiological pathways of disease," Circulation, vol. 109, no. 1, pp. 71-77, 2004.

[6] M. Maclure, "The case-crossover design: a method for studying transient effects on the risk of acute events," American Journal of Epidemiology, vol. 133, no. 2, pp. 144-153, 1991.

[7] H. Janes, L. Sheppard, and T. Lumley, "Case-crossover analyses of air pollution exposure data: referent selection strategies and their implications for bias," Epidemiology, vol. 16, no. 6, pp. 717726, 2005.

[8] D. Bray, P. Monnery, and A. G. Toma, "Airborne environmental pollutant concentration and hospital epistaxis presentation: a 5year review," Clinical Otolaryngology and Allied Sciences, vol. 29, no. 6, pp. 655-658, 2004.

[9] T. O. Ramsay, R. T. Burnett, and D. Krewski, "The effect of concurvity in generalized additive models linking mortality to ambient particulate matter," Epidemiology, vol. 14, no. 1, pp. 1823, 2003. 


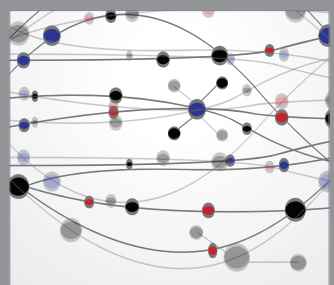

The Scientific World Journal
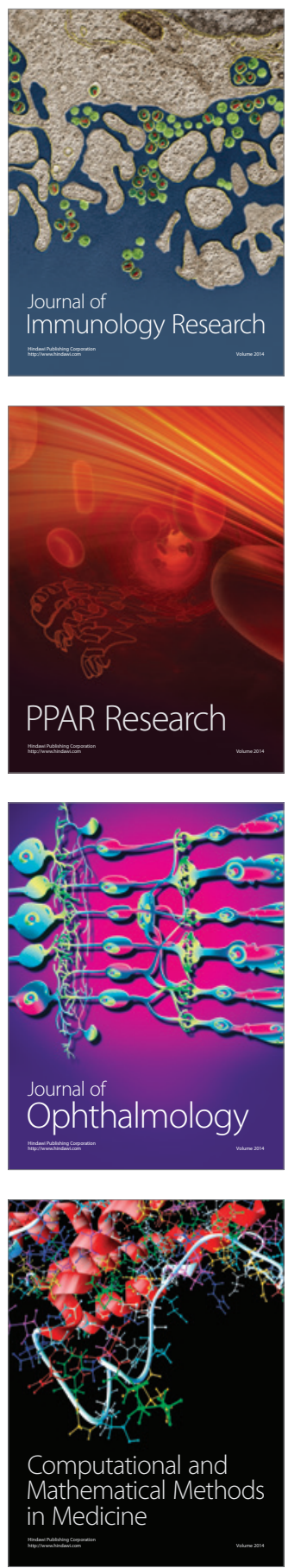

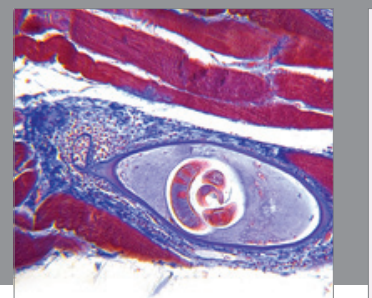

Gastroenterology

Research and Practice
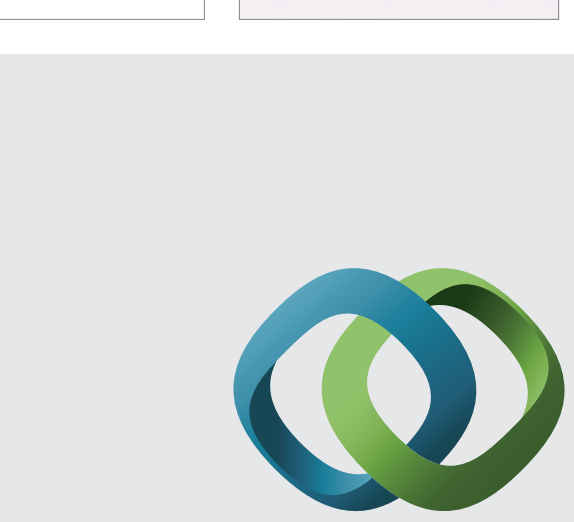

\section{Hindawi}

Submit your manuscripts at

http://www.hindawi.com
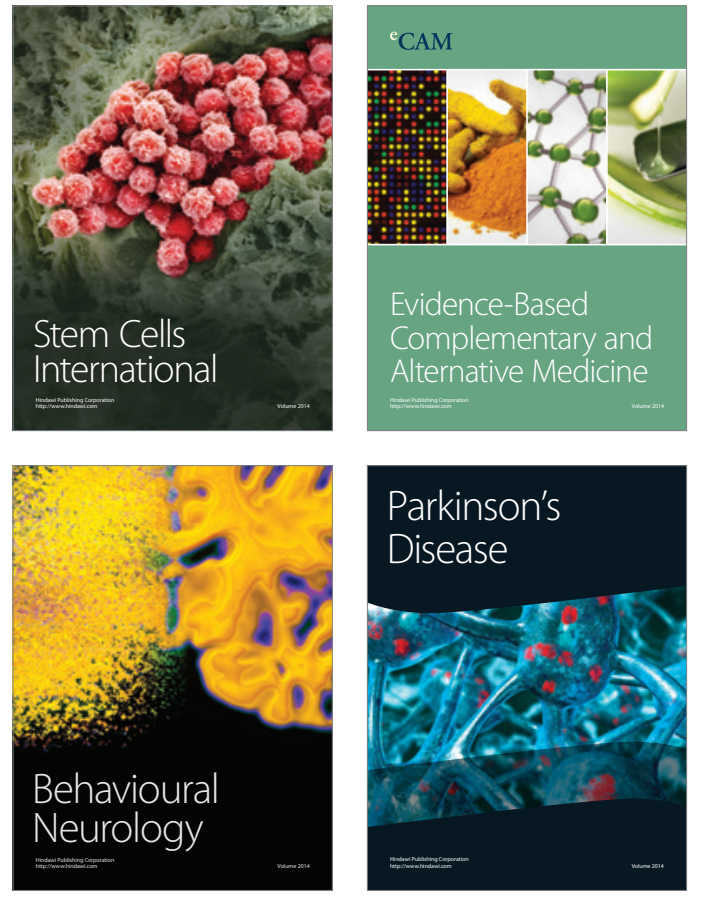
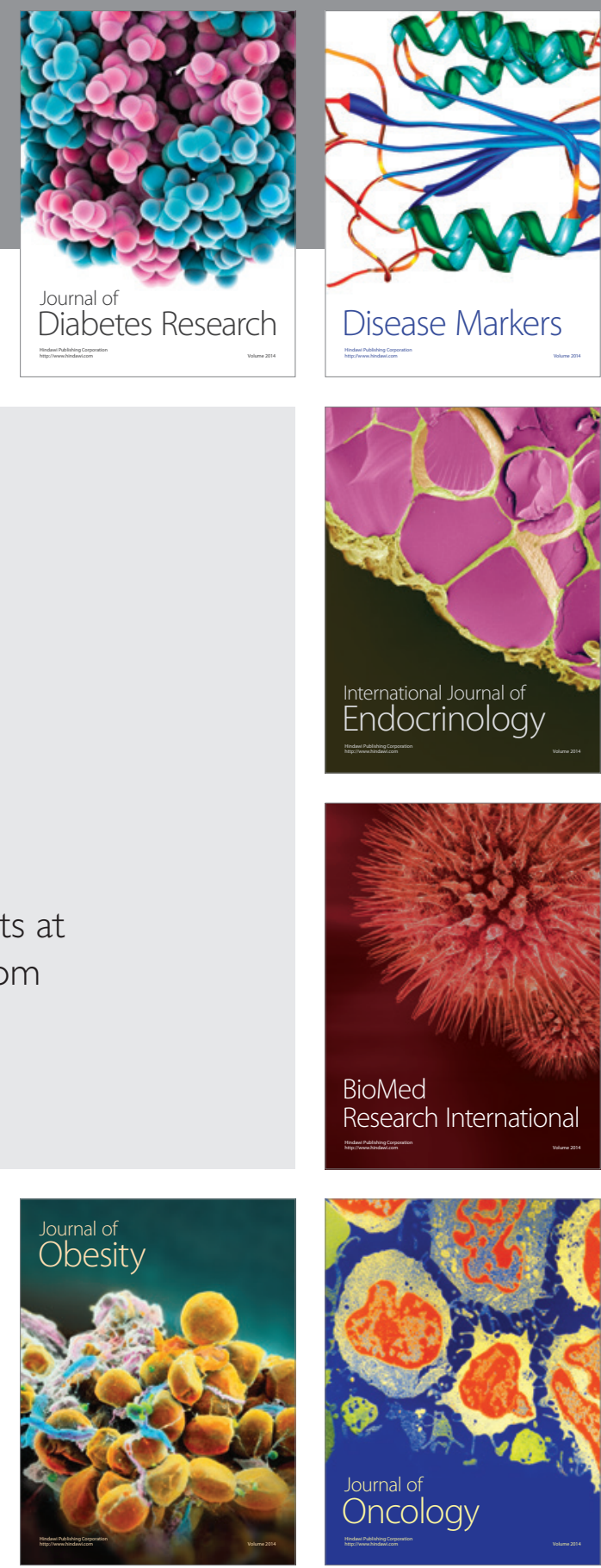

Disease Markers
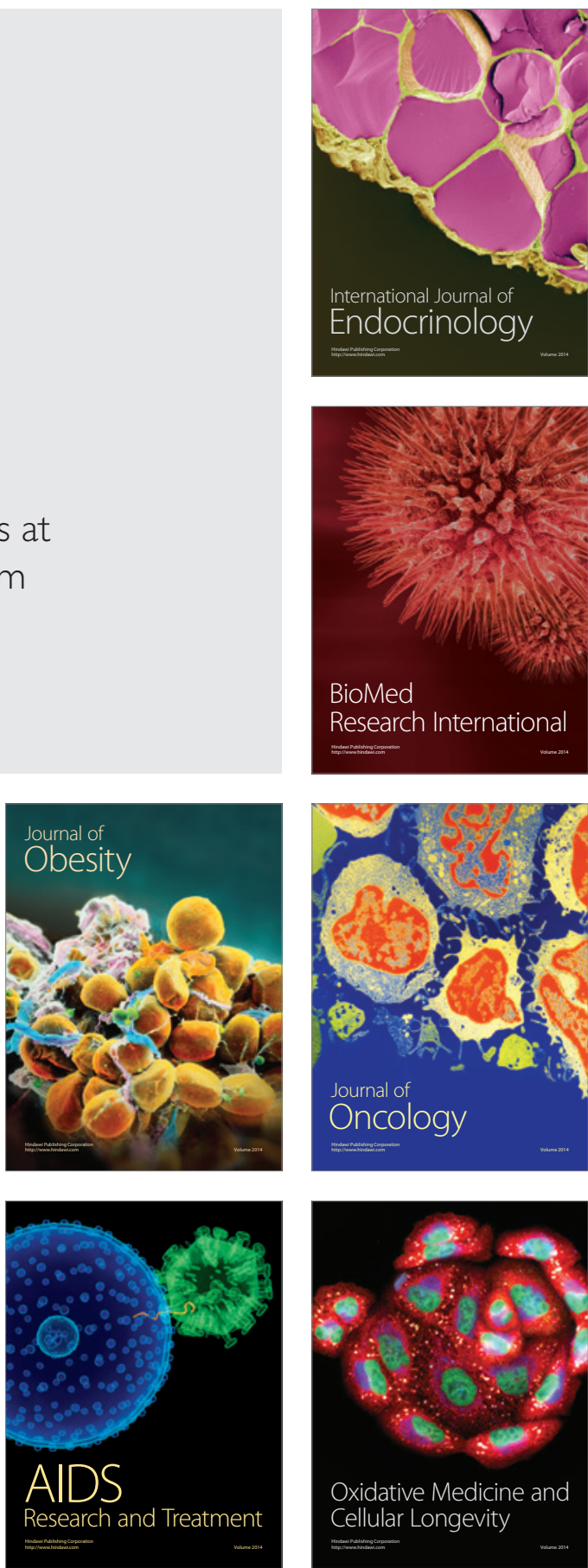